\title{
REVIEW
}

\section{Transsexuals and competitive sports}

\author{
Louis J G Gooren and Mathijs C M Bunck \\ Department of Endocrinology, Section of Andrology, VU University Medical Center, Amsterdam, The Netherlands \\ (Correspondence should be addressed to L J G Gooren; Email: ljg.gooren@vumc.nl)
}

\begin{abstract}
Men generally have an inherent performance advantage over women due to their average greater height and muscle mass and power, as the result of correspondingly different exposures to androgens. Therefore, it is considered fair that in sports men and women compete in separate categories. The question now emerging is whether reassigned transsexuals can compete in fairness with others of their new sex. The pertinent question is how far the previous effects of testosterone in male-tofemale transsexuals $(\mathrm{M}-\mathrm{F})$ are reversible upon androgen deprivation so that $\mathrm{M}-\mathrm{F}$ have no advantage over women, and, vice versa, what the effects are of androgen exposure in female-to-male transsexuals $(\mathrm{F}-\mathrm{M})$ on variables relevant to competition in sports. Before puberty, boys and girls do not differ in height, muscle and bone mass. Recent information shows convincingly that actual levels of circulating testosterone determine largely muscle mass and strength, though with considerable interindividual diversity. This study analyzed the effects of androgen deprivation in $19 \mathrm{M}-\mathrm{F}$ and of androgen administration to $17 \mathrm{~F}-\mathrm{M}$ on muscle mass, hemoglobin $(\mathrm{Hb})$ and insulin-like growth factor-1 (IGF-1). Before cross-sex hormone administration, there was a considerable overlap in muscle mass between $\mathrm{M}-\mathrm{F}$ and $\mathrm{F}-\mathrm{M}$. In both $\mathrm{M}-\mathrm{F}$ and $\mathrm{F}-\mathrm{M}$, height was a strong predictor of muscle mass. Androgen deprivation of $\mathrm{M}-\mathrm{F}$ decreased muscle mass, increasing the overlap with untreated $\mathrm{F}-\mathrm{M}$, but mean muscle mass remained significantly higher in $\mathrm{M}-\mathrm{F}$ than in $\mathrm{F}-\mathrm{M}$. Androgen administration to $\mathrm{F}-\mathrm{M}$ increased muscle mass without inducing an advantage over nontreated $\mathrm{M}-\mathrm{F}$. The conclusion is that androgen deprivation in $\mathrm{M}-\mathrm{F}$ increases the overlap in muscle mass with women but does not reverse it, statistically. The question of whether reassigned $\mathrm{M}-\mathrm{F}$ can fairly compete with women depends on what degree of arbitrariness one wishes to accept, keeping in mind, for instance, that similar blood testosterone levels in men have profoundly different biologic effects on muscle properties, rendering competition in sports intrinsically a matter of how nature endows individuals for this competition.
\end{abstract}

European Journal of Endocrinology $151425-429$

\section{Introduction}

The participation of transsexuals in competitive sports has recently received extensive media attention. The International Olympic Committee now allows sex reassigned transsexuals to compete with members of their new sex.

Men generally have an inherent performance advantage over women due to their average greater height, muscle mass and power. Therefore, it is considered fair that in sports men and women compete in separate categories.

This sex difference is largely based on correspondingly different exposures to androgens. Boys are prenatally and perinatally exposed to androgens. It not known whether this has an impact on future physical traits relevant to sports. But before puberty, boys and girls do not differ in height, muscle and bone mass (1). Testosterone exposure during puberty leads ultimately to an average greater height in men of $12-15 \mathrm{~cm}$, larger bones and muscle mass, and greater strength. Clinical and experimental studies show that androgen deprivation reverses, at least in part, the previous anabolic effects of testosterone on muscle and bone $(2-4)$, while testosterone administration dosedependently increases muscle mass and maximal voluntary strength, but not fatigability or specific tension (3).

Chromosomal sex as the criterion to ensure fair competition in sports has been relinquished as an adequate indicator. There is no evidence that the chromosomal pattern has a direct effect on muscle mass and strength. Rather, the influence seems to be indirect through determination of the nature of the embryonic gonadal anlagen and its hormonal products. Chromosomal sex as the criterion for competition in sports (dropped since 2000) precluded from participation not only transsexuals but also subjects with disorders of sexual 
differentiation. In contemporary medical practice, there is in ultimo no single solid biologic criterion for the determination of sex. When needed for a specific purpose, the best solution seems to be to adopt a criterion that best serves the purpose for which it is needed. In sports, previous and present exposure to androgens is a reasonable criterion for reducing unfair competition, not only between men and women, but also between men, barring men who use or have used exogenous androgens. Bhasin and co-workers have demonstrated that there is a positive correlation between blood testosterone concentrations and leg press strength, thigh and quadriceps muscle volume, and levels of hemoglobin (Hb) and insulin-like growth factor-1 (IGF-1) (4), and that the anabolic response to testosterone can largely be predicted by the dose administered (5).

Increasingly, countries are permitting transsexuals who have undergone sex reassignment to change their legal sex and on that basis to take part in public life with the same rights as anyone else. However, in the case of participation in sports by transsexuals, the further question arises of whether an individual who has undergone normal physical pubertal and postpubertal development in one sex, with prolonged exposure to sex-appropriate levels of sex steroids before surgical sex reassignment (SRS), can fairly compete as a member of the other. In terms of actual androgen hormone levels, male-to-female $(\mathrm{M}-\mathrm{F})$ transsexuals after SRS have no competitive advantage over other women, but the effects of prior androgen exposure on muscle mass and strength do carry over, at least for a certain time period, while previous effects on height and the size of feet and hands are irreversible, and this may be a relevant consideration.

\section{Subjects and methods}

\section{Subjects}

In this retrospective study, we compared the pretreatment measurements in 17 female-to-male transsexuals $(\mathrm{F}-\mathrm{M})$ with the measurements after 1 year of crosssexual treatment in $19 \mathrm{M}-\mathrm{F}$ undergoing sex reassignment therapy, and vice versa. Detailed information on the study protocol and subjects can be found in an earlier report by our group (6). In our clinic, the standard hormone treatment before SRS in $\mathrm{M}-\mathrm{F}$ is the antiandrogen cypoterone acetate $100 \mathrm{mg}$ /day (Androcur; Schering AG, Berlin, Germany) and ethinyl estradiol $100 \mathrm{~g} /$ day (Lynoral, Organon, Oss, The Netherlands). $\mathrm{F}-\mathrm{M}$ receive $250 \mathrm{mg}$ of testosterone esters every 2 weeks (Sustanon, Organon, Oss, The Netherlands). SRS including gonadectomy usually takes place after 2 years of cross-sex hormones. Then, antiandrogen treatment in $\mathrm{M}-\mathrm{F}$ transsexuals is usually stopped, while estrogen treatment continues. After ovariectomy, androgen treatment in $\mathrm{F}-\mathrm{M}$ subjects is continued at a dosage level also administered to hypogonadal men.
In this regard, the situation of $\mathrm{F}-\mathrm{M}$ (and intersexed individuals assigned to the male sex) is comparable to the situation of agonadal/hypogonadal men receiving testosterone replacement. While administration of exogenous testosterone is principally prohibited for participants in competitive sports, it is the policy now to allow medically indicated testosterone replacement in men, provided testosterone blood levels have in the past not exceeded and do presently not exceed those naturally occurring in eugonadal men. The study was approved by the ethical review board of the VU University Medical Center, and all subjects provided informed consent.

\section{Laboratory assays and imaging}

Standardized assays were used to assess the blood samples. A detailed description of the laboratory assays and the magnetic resonance imaging (MRI) protocol used in this study can be found in an earlier publication (6).

\section{Statistical analysis}

Values are presented as means \pm S.D. and 95\% confidence interval (95\% CI). Differences between pretreatment $\mathrm{M}-\mathrm{F}$ and post-treatment $\mathrm{F}-\mathrm{M}$, and pre-treatment $\mathrm{F}-\mathrm{M}$ and post-treatment $\mathrm{M}-\mathrm{F}$ were tested by the nonparametric Mann-Whitney test. In search of other determinants of muscle mass area, we used a univariate linear regression model. After identification of determinants of muscle mass area, we applied multivariate regression analysis to adjust for these determinants in the relation of biologic sex to muscle mass area. The present study is retrospective, and was originally not designed to test the difference in muscle mass between pre-treatment $\mathrm{F}-\mathrm{M}$ and post-treatment $\mathrm{M}-\mathrm{F}$. Therefore, the power of the study was calculated to determine the study's sensitivity. With the difference in muscle mass area between pre-treatment $\mathrm{F}-\mathrm{M}$ and post-treatment $\mathrm{M}-\mathrm{F}$ as primary endpoint and $\alpha$ set at 0.05 , the $\beta$ of the study was 0.1. Statistical analysis was performed with SPSS 11.5 (SPSS, Chicago, IL, USA). P values below 0.05 were considered significant.

\section{Results}

We present our data on the effects of androgen deprivation in $\mathrm{M}-\mathrm{F}$, and of androgen administration to $\mathrm{F}-\mathrm{M}$, on the following variables: plasma testosterone levels, muscle mass measured by MRI at the level of the thigh, and levels of hemoglobin $(\mathrm{Hb})$ and insulinlike growth factor-1 (IGF-1) (Table 1) (7, 8). Crosssex hormone treatment of $\mathrm{M}-\mathrm{F}$ decreased plasma testosterone to castration levels and reduced muscle area significantly after 1 year of treatment, with no further reduction after 3 years of hormones (6). 
Table 1 Changes in plasma testosterone and associated changes in biological variables. All values are means \pm S.D.

\begin{tabular}{|c|c|c|c|c|c|c|}
\hline & \multicolumn{3}{|c|}{ Male-to-female transsexuals $(n=19)$} & \multicolumn{3}{|c|}{ Female-to-male transsexuals $(n=17)$} \\
\hline & Baseline & 1 year & 3 years & Baseline & 1 year & 3 years \\
\hline Plasma testosterone $(\mathrm{nmol} / \mathrm{l})(6)$ & $21.5 \pm 5.8$ & $1.0 \pm 0.0^{*}$ & $0.9 \pm 0.1$ & $1.6 \pm 0.6$ & $30.8 \pm 11.4$ & $30.0 \pm 13.0$ \\
\hline Muscle area $\left(\mathrm{cm}^{2}\right)(6)$ & $306.9 \pm 46.5$ & $277.8 \pm 37.0 *$ & $271.0 \pm 39.0 \S$ & $238.8 \pm 33.1$ & $285.3 \pm 35.6^{*}$ & $280 \pm 39^{*}$ \\
\hline Hemoglobin $\left(\mathrm{mmol} / \mathrm{l}^{\S}\right.$ & $9.3 \pm 0.7$ & $8.0 \pm 0.7^{\star}$ & $8.1 \pm 0.6$ & $8.2 \pm 0.7$ & $9.4 \pm 0.8^{*}$ & $9.3 \pm 0.9$ \\
\hline IGF-1 (7) & $38.0 \pm 10.0$ & $14.0 \pm 8.0^{*}$ & & $26.0 \pm 12.0$ & $36.0 \pm 14.0^{*}$ & \\
\hline
\end{tabular}

* $P<0.05$ baseline vs 1 year (Mann-Whitney test), no significant difference between 1 and 3 years.

$\S$ Unpublished data. Numbers in parentheses correspond to sources in reference list.

Hb levels decreased significantly, and values after 1 and 3 years' hormone administration were not different, and the latter were not different from values in $\mathrm{F}-\mathrm{M}$ before testosterone administration (unpublished data). After 1 year of cross-sex hormones, values of plasma IGF-1 fell significantly to levels lower than in F-M before testosterone administration (8).

In $\mathrm{F}-\mathrm{M}$, testosterone administration increased plasma testosterone levels $(30.8 \pm 11.4 \mathrm{nmol} / \mathrm{l})$, and the values remained within the reference range for eugonadal men $(12.0-28.0 \mathrm{nmol} / \mathrm{l} ; P=0.3)$, although peaks above this range were observed shortly after administration. After 1 year, muscle area and levels of $\mathrm{Hb}$ and IGF-1 (8) were in the same range as in $\mathrm{M}-\mathrm{F}$ before cross-sex hormones, with no further increases in muscle area and $\mathrm{Hb}$ levels after 3 years of testosterone administration (unpublished data). To qualify $\mathrm{F}-\mathrm{M}$ for competition with other men, a testosterone preparation should be chosen that generates plasma testosterone levels in the reference range of eugonadal men.

Before cross-sex hormone administration, there was a large overlap in muscle area between $\mathrm{M}-\mathrm{F}$ and $\mathrm{F}-\mathrm{M}$, but means in $\mathrm{M}-\mathrm{F}$ were significantly higher than in F-M (Fig. 1). After 1 year of androgen deprivation, mean muscle area in $\mathrm{M}-\mathrm{F}$ had decreased significantly but remained significantly greater than in $\mathrm{F}-\mathrm{M}$ before testosterone treatment (Table 2), though with an overlap that was almost complete when androgen-deprived $\mathrm{M}-\mathrm{F}$ were again compared to nontreated $\mathrm{F}-\mathrm{M}$ (Fig. 1). $\mathrm{M}-\mathrm{F}$ were on average $10.7 \mathrm{~cm}$ taller $(95 \%$ CI $5.4-16.0 \mathrm{~cm})$ than $\mathrm{F}-\mathrm{M}(7)$. When androgen-deprived $\mathrm{M}-\mathrm{F}$ were compared to pretreatment $\mathrm{F}-\mathrm{M}$ in a linear regression model, height was a strong predictor of muscle area $(\beta=2.29 ; 95 \%$

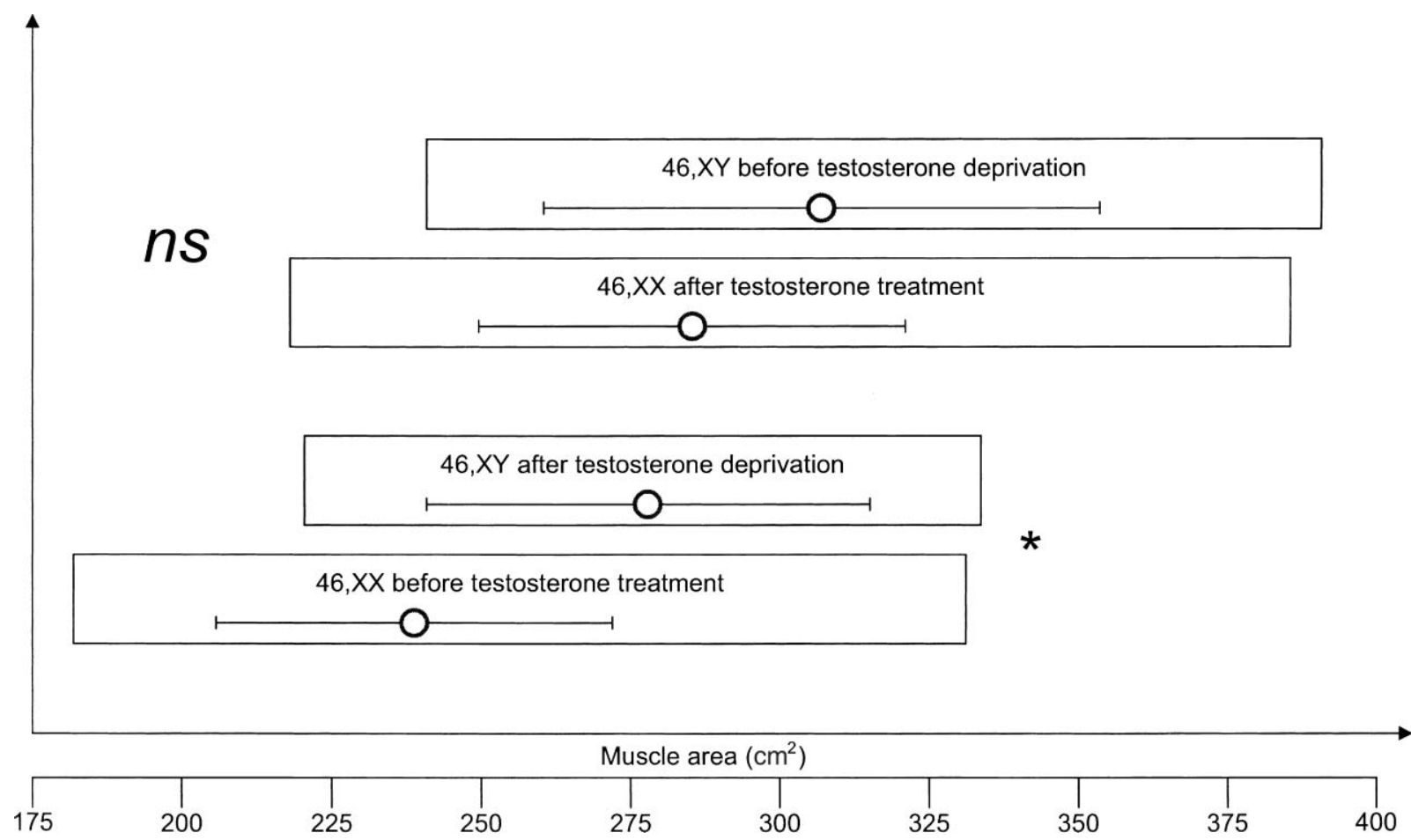

Figure 1 Relative changes in muscle mass after 12-month cross-sex hormonal treatment in 19 male-to-female and 17 female-to-male transsexual subjects. The means of $46, \mathrm{XY}$ before testosterone deprivation and $46, \mathrm{XX}$ before testosterone treatment differ with statistical significance. Beams represent range of all subjects. ${ }^{\star} P<0.05$ Mann-Whitney test asymp. sig. (two-tailed). ns: not statistically significant. Mean in $\mathrm{cm}^{2}$ with S.D. (whiskers). 
Table 2 Effects of testosterone administration/deprivation on anthropometric variables. All values are mean \pm S.D. and $95 \%$ confidence interval of the difference of the mean.

\begin{tabular}{|c|c|c|c|c|c|c|}
\hline & \multicolumn{3}{|c|}{$\begin{array}{l}46, X Y \text { before } T \text { deprivation } \\
\text { vs } 46, X X \text { after } T \text { treatment }\end{array}$} & \multicolumn{3}{|c|}{$\begin{array}{c}46, X Y \text { after } T \text { deprivation } \\
\text { vs } 46, X X \text { before } T \text { treatment }\end{array}$} \\
\hline & $\begin{array}{c}46, \mathrm{XY} \\
(n=19)\end{array}$ & $\begin{array}{c}46, \mathrm{XX} \\
(n=17)\end{array}$ & $\begin{array}{l}95 \% \mathrm{Cl} \\
\text { of the difference }\end{array}$ & $\begin{array}{c}46, \mathrm{XY} \\
(n=19)\end{array}$ & $\begin{array}{c}46, \mathrm{XX} \\
(n=17)\end{array}$ & $\begin{array}{c}95 \% \mathrm{Cl} \\
\text { of the difference }\end{array}$ \\
\hline Height (cm) (6) & $177.8 \pm 7.9$ & $167.1 \pm 7.8$ & $5.4-16.0 *$ & $177.8 \pm 7.9$ & $167.1 \pm 7.8$ & $5.8-16.0 *$ \\
\hline Body weight (kg) (6) & $66.1 \pm 11.7$ & $63.4 \pm 11.4$ & $-5.1-10.4$ & $69.9 \pm 11.3$ & $60.7 \pm 11.8$ & $1.40-16.8^{*}$ \\
\hline Body mass index $\left(\mathrm{kg} / \mathrm{m}^{2}\right)(6)$ & $20.8 \pm 2.6$ & $22.6 \pm 3.0$ & $-3.7-0.1$ & $22.0 \pm 2.7$ & $21.7 \pm 3.5$ & $-1.7-2.4$ \\
\hline Muscle area $\left(\mathrm{cm}^{2}\right)(6)$ & $306.9 \pm 46.5$ & $285.3 \pm 35.6$ & $-6.4-49.5$ & $277.8 \pm 37.0$ & $238.8 \pm 33.1$ & $15.1-62.9^{\star}$ \\
\hline Serum testosterone $(\mathrm{nmol} / \mathrm{l})(6)$ & $21.5 \pm 5.8$ & $30.8 \pm 11.4$ & $-15.7-3.0^{\star}$ & $1.0 \pm 0.0$ & $1.6 \pm 0.6$ & $-0.9-0.3^{*}$ \\
\hline
\end{tabular}

* $P<0.5$ vs baseline (Mann-Whitney test)

$\mathrm{T}$ : testosterone. Numbers in parentheses correspond to sources in reference list.

CI 1.06-3.53; $P=0.001)$. After correction for the effect of gender, the relation between height and muscle area remained significant $(\beta=1.63 ; 95 \% \mathrm{CI}$ $0.12-3.14 ; P=0.036)$.

\section{Discussion}

The physical changes resulting from cross-sex hormone administration in transsexuals have been reported in scientific publications (6-8). Administration of crosssex hormone has a profound impact on physical features, such as muscle mass and fat distribution, and on biochemical variables, such as $\mathrm{Hb}$ and IGF-1. These changes took place during the first year of administration of cross-sex hormones, with no further differences when measured 2 years later. This contrasts with pubertal virilization/feminization, which is much more protracted. The difference in course of development could be due to the high doses of cross-sex hormones in transsexuals.

The pivotal question is this: can reassigned transsexuals compete fairly with others of their new sex? Our data are limited and do not provide insight into all pertinent aspects. In competitive sports, in all likelihood, small differences may be critical for winning or losing. Our analysis is not refined enough to detect these small differences, allowing only an approximation. As far as our data allow conclusions, the answer for $\mathrm{F}-\mathrm{M}$ is probably yes, provided the administration of testosterone has not generated and does not generate supraphysiological testosterone levels, as these levels and exercise induce a surplus in muscle mass over exercise alone $(3-5,9)$. For $\mathrm{M}-\mathrm{F}$, there is an element of arbitrariness. There is no conclusive evidence pro or con that the prenatal/perinatal testosterone exposure of men has an impact on future physical traits. Androgen deprivation in $\mathrm{M}-\mathrm{F}$ induces a loss of muscle area, but mean muscle area remained larger in reassigned $\mathrm{M}-\mathrm{F}$ than in untreated $\mathrm{F}-\mathrm{M}$, though with an almost complete overlap. This overlap between $\mathrm{M}-\mathrm{F}$ and $\mathrm{F}-\mathrm{M}$ existed even before cross-sex hormones, although not as extensively as after treatment. In real life, there will always be an element of arbitrariness in the drawing of competitive lines. Different individuals are born with and develop postnatally different potentials. The caprices of genetics and postnatal development will make any form of competition intrinsically unfair at some level. In the studies of Bhasin and colleagues $(3-5,9)$, changes in muscle size correlated with testosterone dose and concentration. These correlations were established in groups of men receiving graded doses of testosterone. Nevertheless, there was considerable heterogeneity in response to testosterone administration within each group of men receiving the same amount of testosterone. These individual differences in response to androgen administration might reflect differences in activity level, testosterone metabolism and nutrition, or polymorphisms in androgen receptor, myostatin, $5 \alpha$-reductase or other muscle growth regulators, all genetically determined and inherently personal. The implication is that all men and women are not born equally endowed for competition in sports. Another consideration is that testosterone-related physical properties are not relevant to all types of sports.

We may summarize as follows:

1. Testosterone exposure has profound effects on muscle mass and strength, justifying the practice that men and women compete in sports in separate categories.

2. The response to testosterone exposure in men is idiosyncratic; similar plasma levels of testosterone do not produce similar effects on muscle mass and strength.

3. The effects of cross-sex hormones in the dosages commonly used have reached their maximum effects after 1 year of administration.

4. In spite of a large difference in testosterone exposure between men and women, there is a large overlap of muscle area between them.

5. Androgen deprivation of men induces a loss of muscle area, further increasing this overlap with women.

6. Therefore, depending on the levels of arbitrariness one wants to accept, it is justifiable that reassigned $\mathrm{M}-\mathrm{F}$ compete with other women. 


\section{References}

1 Jones G \& Dwyer T. Bone mass in prepubertal children: gender differences and the role of physical activity and sunlight exposure. Journal of Clinical Endocrinology and Metabolism $1998 \mathbf{8 3}$ 4274-4279.

2 Mauras N, Hayes V, Welch S, Rini A, Helgeson K, Dokler M, Veldhuis JD \& Urban RJ. Testosterone deficiency in young men: marked alterations in whole body protein kinetics, strength, and adiposity. Journal of Clinical Endocrinology and Metabolism 1998 83 1886-1892.

3 Storer TW, Magliano L, Woodhouse L, Lee ML, Dzekov C, Dzekov J, Casaburi R \& Bhasin S. Testosterone dose-dependently increases maximal voluntary strength and leg power, but does not affect fatigability or specific tension. Journal of Clinical Endocrinology and Metabolism $2003 \mathbf{8 8} 1478-1485$.

4 Bhasin S, Woodhouse L, Casaburi R, Singh AB, Bhasin D, Berman N, Chen X, Yarasheski KE, Magliano L, Dzekov C, Dzekov J, Bross R, Phillips J, Sinha-Hikim I, Shen R \& Storer TW. Testosterone dose-response relationships in healthy young men. American Journal of Physiology, Endocrinology, and Metabolism 2001281 E1172-E1181.

5 Woodhouse LJ, Reisz-Porszasz S, Javanbakht M, Storer TW, Lee M, Zerounian H \& Bhasin S. Development of models to predict anabolic response to testosterone administration in healthy young men.
American Journal of Physiology, Endocrinology, and Metabolism 2003284 E1009-E1017.

6 Elbers JM, Asscheman H, Seidell JC, Megens JA \& Gooren LJ. Long-term testosterone administration increases visceral fat in female to male transsexuals. Journal of Clinical Endocrinology and Metabolism 199782 2044-2047.

7 Elbers JM, Asscheman H, Seidell JC \& Gooren LJ. Effects of sex steroid hormones on regional fat depots as assessed by magnetic resonance imaging in transsexuals. American Journal of Physiology, Endocrinology, and Metabolism 1999276 E317-E325.

8 van Kesteren P, Lips P, Deville W, Popp-Snijders C, Asscheman H, Megens J \& Gooren L. The effect of one-year cross-sex hormonal treatment on bone metabolism and serum insulin-like growth factor-1 in transsexuals. Journal of Clinical Endocrinology and Metabolism $1996812227-2232$.

9 Bhasin S, Storer TW, Berman N, Callegari C, Clevenger B, Phillips J, Bunnell TJ, Tricker R, Shirazi A \& Casaburi R. The effects of supraphysiologic doses of testosterone on muscle size and strength in normal men. New England Journal of Medicine 1996335 1-7.

Received 27 April 2004

Accepted 7 July 2004 